\title{
CANCER, CHEMOTHERAPY AND ANAESTHESIA
}

\author{
Frances Chung
}

\begin{abstract}
Cancer patients coming to operation can suffer from multiple systemic problems which may complicate the anaesthetic management. Interactions between anaesthetics and cytotoxjc agents can occur. Patients may have increased sensitivity to general anaesthetics, and prolonged neuromuscular blockade might occur after muscle relaxants.
\end{abstract}

KEY WoRDS: ANAESTHESIA, complications, chemotherapy; CHEMOTHERAPY, cancer, anaesthesia.

THE MODERN ERA of chemotherapy was ushered in by the introduction of alkylating agents in the 1940s. In the past four decades, there has been rapid growth in the field of chemotherapy. ${ }^{1}$ Apparent cures have been achieved with chemotherapy in patients with some types of cancer, and other patients have benefited in terms of palliation of symptoms and extension of life. ${ }^{2}$ Notable examples are patients with Hodgkin's disease and leukaemia, and an increasing number of solid tumours in children and adults.

With the prolongation of survival in cancer patients, chances for emergency or elective operations are much increased. Patients may be on chemotherapy when the tumour is large and non-resectable and then, after it has shrunk in size, resection might be possible and continuation of chemotherapy would then be more effective. In cases of terminal malignant disease, patients may require palliative procedures such as decortication for persistent pleural effusion, creation of a pleuropericardial window for recurrent or rapidly progressive pericardial effusion, or neurosurgical procedures such as cordotomy or rhizotomy for control of persistent pain. It is important that anaesthetists and surgeons should have a good understanding of the systemic effects of cancer, the effects of metastases, the side effects of chemotherapy and its interactions with anaesthetics.

Drugs currently used in chemotherapy of malignant diseases may be arbitrarily divided

Frances Chung, M.D., F.R.C.P. (C), Lecturer, Department of Anaesthesia, University of Toronto and Department of Anaesthesia, Toronto Western Hospital, 399 Bathurst Street, Toronto, Ontario M5T 2S8.

Can. Anaesth. Soc. J., vol. 29, no. 4, July 1982 into several classes, ${ }^{3}$ and agents that are generally used are listed in Table I.

The anaesthetic implications of the hazards associated with the management of cancer patients will be discussed in relationship to the preoperative, operative and postoperative periods. The chemotherapeutic agents mentioned in this text are those that have specific relevance to anaesthesia.

\section{Preoperative Period}

Careful assessment and management of cancer patients is important in the preoperative period to set the stage for management during operation and in the postoperative period.

\section{Cardiovascular Status}

Cancer patients can develop pericardial effusion as a result of malignancy or congestive heart failure. Serious cardiac toxicity has been documented for cyclophosphamide, ${ }^{4}$ cisplastin ${ }^{5}$ and, especially, adriamycin. ${ }^{6}$

Cardiac toxicity may manifest itself in electrocardiographic (ECG) abnormalities or cardiomyopathy. Isolated transient ECG changes have been observed in 11 per cent of patients receiving adriamycin. Findings include supraventricular tachycardia, atrial and ventricular extrasystoles, decreased QRS voltages, and ST$T$ wave changes. Sudden death has been reported in patients treated with anthracycline. ${ }^{7}$ These abnormalities do not appear to be dose-related and can occur during or after therapy. With withdrawal of the drug, the ECG usually returns to the pretreatment pattern.

The incidence of clinically diagnosed 364 adriamycin-induced congestive heart failure is 
TABLE I

Classes of Chemotherapeutic Agents and Immunotherapeutic agents

\begin{tabular}{|c|c|c|}
\hline Class of compound & Type of agent & Non-proprietary Names \\
\hline Aklylating agents & $\begin{array}{l}\text { Ethylenimine derivatives } \\
\text { Alkyl sulphonates } \\
\text { Nitrosoureas }\end{array}$ & $\begin{array}{l}\text { Mechlorethamine } \\
\text { Cyclophosphamide } \\
\text { Melphalan } \\
\text { Uracil mustard } \\
\text { Chlorambucil } \\
\text { Thiotepa } \\
\text { Busulfan } \\
\text { Carmustine (BCNU) } \\
\text { Lomustine (CCNU) } \\
\text { Semustine (Methyl CCNU) } \\
\text { Streptozotocin } \\
\text { Dacarbazine }\end{array}$ \\
\hline Antimetabolites & $\begin{array}{l}\text { Folic acid analogs } \\
\text { Pyrimidine analogs } \\
\text { Purine analogs }\end{array}$ & $\begin{array}{l}\text { Methotrexate } \\
\text { Fluorouracil } \\
\text { Cytarabine (Cytosine arabinoside) } \\
\text { Mercaptopurine } \\
\text { Thioguanine }\end{array}$ \\
\hline Natural products & $\begin{array}{l}\text { Vinca alkaloids } \\
\text { Antibiotics }\end{array}$ & $\begin{array}{l}\text { Vinblastine } \\
\text { Vincristine } \\
\text { Dactinomycin } \\
\text { Daunorubicin } \\
\text { Doxorubicin (Adriamycin) } \\
\text { Bleomycin } \\
\text { Mithramycin } \\
\text { Mitomycin C } \\
\text { L-Asparaginase }\end{array}$ \\
\hline Miscellaneous agents & $\begin{array}{l}\text { Substituted urea } \\
\text { Methy hydrazine } \\
\text { Derivative } \\
\text { Adrenocortical suppressant } \\
\text { Cisplatinum }\end{array}$ & $\begin{array}{l}\text { Hydroxyurea } \\
\text { Procarbazine } \\
\text { Mitotane } \\
\text { Cisplatinum }\end{array}$ \\
\hline Hormones & $\begin{array}{l}\text { Adrenocorticosteroids } \\
\text { Progestins }\end{array}$ & $\begin{array}{l}\text { Prednisone } \\
\text { Hydroxyprogesterone Caproate } \\
\text { (Dalalutin) } \\
\text { Medroprogesterone acetate } \\
\text { Megestrol acetate (provera) } \\
\text { Diethylstilbestrol } \\
\text { Ethinylestradiol (Estinyl) } \\
\text { Testosterone propionate } \\
\text { Fluoxymesterone (Halotestin) }\end{array}$ \\
\hline Immunotherapy & & $\begin{array}{l}\text { Vaccines from BCG } \\
\text { (Bacillus Calmette Guerin) } \\
\text { Vaccines from Corynebacterium } \\
\text { parvum. }\end{array}$ \\
\hline
\end{tabular}

2.2 per cent. $^{8}$ In one series the incidence of cardiomyopathy increased to 25 per cent at doses of adriamycin over $550 \mathrm{mg} / \mathrm{m}^{2}$. There was a significant association between propranolol and adriamycin in the causation of death. ${ }^{9}$ Patients who have received high doses of radiation therapy to the mediastinum and those who are on cyclophosphamide therapy are more susceptible to adriamycin cardiomyopathy. Prior heart disease may increase the risk. ${ }^{10}$ The syndrome is characterized by the onset of the classical symp- toms and signs of biventricular failure. The ECG shows a generalized diminution in QRS voltage. Cardiac function tests such as systolic times intervals ${ }^{11}$ and echocardiograms ${ }^{12}$ show findings typical of decreased myocardial contractility and can be used to detect early myocardial dysfunction.

The onset of congestive heart failure is commonly delayed one to six months following completion of treatment. When congestive heart failure develops it is usually irreversible and 
resistant to standard treatment with digitalis and diuretics.

Thus cancer patients should be examined for clinical evidence of right and left ventricular failure with peripheral and pleural fluid accumulation, resting and exertional dyspnoea, prominent fatigue, pulmonary rales, and S3 gallop. A preoperative ECG and cardiothoracic ratio estimation from the chest film should be done.

\section{Respiratory Status}

Metastases can occur in the lungs. Cancer patients may have atelectasis with bronchial obstruction from tumour, or pneumothorax with tumour necrosis. Pleural effusion can develop.

Although an unusual form of toxicity, profound pulmonary disturbances such as pneumonitis and pulmonary fibrosis may be induced by some alkylating agents such as busulfan, ${ }^{13}$ cyclophosphamide, chlorambucil, ${ }^{15}$ methotrexate, ${ }^{16}$ cytarabine, mitomycin $\mathrm{C}$, carmustine, but the most important and common cause of this complication is bleomycin. ${ }^{17}$

Approximately five to ten per cent of patients treated with bleomycin develop significant pulmonary complications, varying from decreased pulmonary function to severe pulmonary fibrosis and death. The clinical toxicity bears a relationship to total dose. As the dose approaches $500 \mathrm{mg}$ there is a substantial increase in the incidence of pulmonary toxicity. Patients over 70 are much more susceptible to bleomycin pulmonary toxicity than younger patients. It is also enhanced by previous pulmonary radiation therapy and underlying lung diseases.

The onset of pulmonary toxicity is usually delayed, occurring between four and ten weeks after initiation of therapy. The clinical presentation is a non-productive cough, dyspnoea and tachypnoea. On physical examination, fine inspiratory rales may be heard. Blood gases show arterial hypoxaemia, and pulmonary function studies show decreased diffusion capacity and restrictive pulmonary disease. The radiological presentation is typical of interstitial pneumonitis, which may progress to pulmonary fibrosis. ${ }^{18}$

Dyspnoea, cough, hyperventilation, decreased air entry or crepitations on auscultation are signs and symptoms requiring attention. A preoperative chest $\mathrm{X}$-ray is essential. If there is any abnormality, preoperative blood gas analysis and pulmonary function tests should be done. These preoperative values will serve as guides for management of ventilation during the operative and postoperative periods.

\section{Gastrointestinal Disturbances}

Many patients with advanced malignancy have anorexia, nausea and cachexia. Cachexia is frequently the most disabling feature of cancer and the most frequent cause of death. ${ }^{19}$ Thus with wasting of body tissues, poor nutritional status and low albumin levels, cancer patients have increased sensitivity to anaesthetics.

Many chemotherapeutic agents produce anorexia, nausea, toxicity and diarrhoea within minutes to hours of administration. The symptoms usually subside within hours. Several drugs such as methotrexate, ${ }^{20}$ flurouracil ${ }^{21}$ have the capacity to damage the oral and gastrointestinal mucosa. This might produce stomatitis, dysphagia, or diarrhoea days to weeks after the start of treatment. Assessment of fluid and electrolytes before operation is important. Occasionally, intravenous fluid therapy might be required to replace water and electrolyte loss.

\section{Hepatic Function}

Metastasis to the liver can occur. Hepatic damage may be caused by a number of agents including 6 mercaptopurine, ${ }^{22}$ cyclophophamide, ${ }^{23}$ methotrexate, ${ }^{24}$ adriamycin, mithramycin, ${ }^{25}$-asparaginase ${ }^{26}$ and nitrosoureas. ${ }^{27}$ In the oral therapy in leukaemia, methotrexate has been found to produce cirrhosis of the liver. The prevalence of cirrhosis was significantly greater in patients treated with frequent small doses than in those receiving a schedule of intermittent large dosage. Additional risk factors include duration of therapy and amount of alcohol intake. 6 Mercaptopurine has produced liver cell necrosis or cholestasis in a few cases of active leukaemia. Hepatotoxicity is usually heralded by elevations in serum transaminase levels, at times accompanied by increases in serum alkaline phosphatase and bilirubin.

\section{Renal Function}

The kidney can be damaged by high doses of methotrexate $^{28}$ mercaptopurine ${ }^{29}$ streptozoto$\operatorname{cin}^{30}$ and by standard doses of mithramycin ${ }^{25}$ and cisplatin. ${ }^{31}$ Preoperative determination of serum creatinine is necessary.

\section{HAEMOPOIETIC FUnCTION}

\section{Anaemia}

Anaemia can develop in cancer patients by many different mechanisms including blood loss, haemolysis, non-haemolytic shortening of red cell survival and decreased red cell produc- 
tion and side effects of chemotherapy. A determination of preoperative haemoglobin is mandatory. The preoperative haemoglobin should be brought to at least $10 \mathrm{gm}$ per cent for elective operations.

The presence of anaemia indicates a definite decrease in oxygen carrying capacity and oxygen availability. Anaemic patients withstand slight degrees of hypoxia and blood loss poorly.

\section{Granulocytopenia}

Granulocytopenia may develop as a side effect of chemotherapy. Patients with neoplastic diseases have an increased incidence of infection with the usual pathogenic organisms as well as with unusual or opportunistic pathogens. This increased susceptibility is related to diseaseinduced alteration in the host defence mechanism, and to immunosuppression induced by radiation or chemotherapy. ${ }^{32}$ Increased precaution in sterility should be exercised in anaesthetic and surgical techniques.

\section{Thrombocytopenia}

Thrombocytopenia may occur as a side effect of chemotherapy. Bleeding might occur with platelet counts of less than 40,000 per cubic millimeter and preoperative prophylactic administration of platelet concentrates might be necessary.

\section{Hypercoagulability}

Patients with neoplasms may present clinical evidence of a hypercoagulable state including an increased incidence of deep vein thrombophlebitis and thromboembolic problems and, in extreme cases, the hypercoagulable state "disseminated intravascular coagulation", ${ }^{33}$

A thrombotic tendency has been noted in association with many types of neoplasm, particularly those of the stomach, pancreas, ovary, lung and colon. Ambulation should be encouraged preoperatively and postoperatively to reduce the risk of thromboembolic problems.

The neoplasms most frequently associated with disseminated intravascular coagulation are carcinoma of the prostate and mucin-producing adenocarcinomata. ${ }^{34}$ Primary fibrinogenolysis is unusual except following prostatic operations.

Coagulation defects may be caused by mechlorethamine, mithramycin, and 1-asparaginase. Fatal haemorrhagic diatheses occur in one to five per cent of patients treated with mithramycin. ${ }^{35}$ They may present with epistaxis, ecchymosis, haematemesis or malaena, or bleeding at needle puncture sites. Vascular damage, thrombocytopenia, altered platelet function, depression of factors $2,5,7,10$ and increase in fibrinolytic activity all contribute to bleeding. Treatment of bleeding consists of discontinuance of mithramycin therapy, massive doses of parenterally administered phytonadione and transfusion of platelets, or fresh whole blood. ${ }^{25}$

Therefore, any evidence of abnormal preoperative, intraoperative and postoperative bleeding calls for a coagulation screen.

\section{Metabolic Disturbances}

Tumours of mesenchymal origin, such as fibrosarcoma, benign fibroma, and liver cell carcinoma, can be associated with hypoglycaemia. ${ }^{36}$ Thus these patients should be given adequate dextrose preoperatively and during operation.

Electrolyte disturbances might occur, which can interfere with the action of anaesthetic drugs. Tissue breakdown may cause large quantities of potassium to be released, resulting in hyperkalaemia. Hypercalcaemia can develop due to lysis of bone by osseous metastases. Hypocalcaemia is seen in medullary carcinoma of thyroid, small cell carcinoma of the lung, ${ }^{37}$ and it could also be the result of calcium uptake into osteoblastic metastases, ${ }^{38}$ malabsorption, renal insufficiency, hypomagnesaemia, and anticancer agents. ${ }^{39}$

The syndrome of inappropriate antidiuretic hormone reaction has been observed in patients receiving cyclophosphamide and vincristine. ${ }^{3}$ It is important to be aware of the possibility of water intoxication.

\section{Endocrine Disorders}

Besides its well known association with phaeochromocytoma, neuroblastoma, and aldosteronoma, hypertension has been reported in association with renal neoplasms, including haemangiopericytoma, Wilm's tumour and renal cell carcinoma. ${ }^{40}$ Endocrine disturbances such as Cushing's syndrome, inappropriate secretion of antidiuretic hormone, diabetes insipidus, carcinoid syndrome can occur. ${ }^{41}$

\section{Central Nervous Disturbances}

\section{Neuropathy}

A neuropathy can be expected to develop in 16 per cent of patients with cancer. ${ }^{42}$ The neuropathy may be motor in which it may resemble 
TABLE II

Interaction Between Anaesthetic and Cytotoxic Agents

\begin{tabular}{|c|c|c|}
\hline $\begin{array}{c}\text { Cytotoxic and } \\
\text { immunosuppressive } \\
\text { agents }\end{array}$ & Anaesthetic agents & Effects \\
\hline c. parvum & $\begin{array}{l}\text { pentobarbitone } \\
\text { tribromoethanol }\end{array}$ & Lethal in mice \\
\hline \multirow[t]{2}{*}{ procarbazine } & barbiturates & enhancement of CNS depressants \\
\hline & sympathomimetics & ? hypertensive episodes \\
\hline cyclophosphamide & succinylcholine & prolonged apnoea \\
\hline azathioprine & curare & reduced potency \\
\hline alkylating agents & & $\begin{array}{l}? \text { potentiation of neuromuscular } \\
\text { blockade }\end{array}$ \\
\hline bleomycin & oxygen & $\begin{array}{l}\text { adult respiratory distress } \\
\text { syndrome }\end{array}$ \\
\hline
\end{tabular}

amyotrophic lateral sclerosis ${ }^{43}$ or it may be sensory, but in most cases it affects both modalities. Vincristine, ${ }^{44}$ vinblastine, procarbazine, cisplatin, ${ }^{45}$ all can cause a toxic neuropathy with parathesiae, loss of deep tendon reflexes and muscle weakness. Autonomic neuropathy with orthostatic hypotension is a rare concomitant of neoplasia. ${ }^{46}$

\section{Myasthenia Gravis}

Myasthenia gravis has been reported in rare cases of small cell carcinoma of the lung, other kinds of carcinoma, and lymphoma. ${ }^{43}$

\section{Myasthenic Syndrome}

Eaton and Lambert described a syndrome, associated with nonthymic neoplasms, especially small cell carcinoma of the lung. ${ }^{47}$ Unlike myasthenia gravis, this syndrome is usually not accompanied by ptosis or respiratory weakness, the tendon reflexes are often reduced, and repeated contractions initially cause increase strength. ${ }^{48}$

\section{Spinal Cord Metastases}

Spinal metastases do not directly involve the spinal cord, but might compress it from the epidural space. The most common presenting symptom of cord compression is pain and leg weakness. A preoperative neurological assessment is necessary and provides a baseline for postoperative assessment of the patients condition.

\section{Anaesthetic Management}

The anaesthetic management of cancer patients requires an understanding of the possible drug interactions between anaesthetics and cytotoxic agents. The possible interactions are summarised in Table II.

\section{General Anaesthetics}

The hepatic microsomal mixed function oxidase (MFO) system plays a major role in the biotransformation of various drugs, and the system can be stimulated or inhibited by drugs. Many drugs are metabolized by hepatic mixed function oxidase, including some analgesics, sedatives, and antitumour drugs such as cyclophosphamide. It is thus possible that patients receiving certain types of chemotherapy or immunotherapy would be sensitive to normally safe doses of sedatives or anaesthetic agents. ${ }^{49}$

Mice given Corynebacterium parvum, an immunosuppressive agent, become lethally sensitive to normal safe anaesthetic dose of pentobarbitone (Nembutal ${ }^{\circledR}$ ) and tribromoethanol (Avertin). Pentobarbitone and tribromoethanol are detoxified in the liver. C. parvum apparently interferes with the process of detoxification and anaesthetic death may ensue. ${ }^{50}$

Procarbazine augments the effect of central nervous depressants such as phenothiazines, barbiturates, and narcotics. ${ }^{3}$

\section{Muscle Relaxants}

\section{Succinylcholine}

Serum cholinesterase activity is significantly depressed in patients with neoplastic diseases. It is postulated that carcinomatous tissue produces or activates an inhibitor of serum cholinesterase, but this might also be related to depressed protein synthesis by the liver. ${ }^{51}$ 
Cyclophosphamide decreases serum cholinesterase. ${ }^{52} \mathrm{~A}$ number of cases of prolonged apnoea after succinylcholine due to interaction with cyclophosphamide have been reported. ${ }^{53,54}$

Prolonged apnoea following succinylcholine in cancer patients receiving $\mathrm{AB} 132$ has also been reported.$^{55}$ Cholinesterase activity does not return to normal until thirty to forty days after the cessation of $\mathrm{AB} 132$ therapy.

Thiotepa also decreases serum cholinesterase level, ${ }^{52}$ but it is not known whether levels are depressed sufficiently to prolong the effect of succinylcholine. In vitro study seems to indicate that thiotepa is not a very potent inhibitor of serum cholinesterase. ${ }^{56}$

\section{Non-depolarizing Muscle Relaxants}

Patients receiving immuno-suppressive therapy were found to require two to four times the anticipated dose of muscle relaxant. The potency of curare was reported to be reduced by azathioprine (Imuran) both alone, and when combined with guanethedine. 57

A patient who had cystadenoma of the ovary, myasthenia gravis and thiotepa treatment was reported to have had prolonged apnoea after minute doses of pancuronium. ${ }^{58}$

The molecular configuration of alkylating drugs is one of many tertiary ammonium groups, which undergo intramolecular cyclization with formation of quarternary ammonium groups, resulting in an ethylenimonium intermediary. It inhibits choline intake and produces a longlasting hemicholinium-like neuromuscular blockade which is not significantly improved by treatment with physostigmine. ${ }^{59}$ The ethylenimonium form has been shown to cause presynaptic irreversible blockade of neural transmission in the isolated rat phrenic nerve diaphragm preparation and in the intact rat. Little evidence is presently available that this would cause presynaptic neuromuscular blockade in man. ${ }^{60}$

The effects of non-depolarizing muscle relaxants are also potentiated in cancer patients with myasthenia gravis, myasthenic syndrome or dermatomyositis.

\section{Sympathomimetics}

Animal studies indicate that procarbazine inhibits monoamine oxidase. ${ }^{61}$ If procarbazine inhibits monoamine oxidase in man, one would expect potentially dangerous hypertensive episodes with administration of indirect-acting sympathomimetics, such as amphetamine and ephedrine, but there is no conclusive clinical report to that effect as yet. ${ }^{62}$ However, sympathomimetics should be used cautionally, if at all, in patients receiving procarbazine.

\section{Oxygen}

It has been reported that five patients who had received bleomycin 6-12 months before operation developed severe respiratory distress three to five days later. ${ }^{63}$ Despite intensive respiratory support, all five patients died from a rapidly progressing interstitial pneumonia. Postmortem findings were characteristic of those attributed to the adult respiratory distress syndrome.

Another series reports 12 patients who had received bleomycin treatment before retroperitoneal node dissection or multiple wedge resection of the lung for dysgenetic neoplasm of the male gonads or teratocarcinoma of the testicles. $\mathrm{FIO}_{2}$ was maintained at 0.22 to 0.25 throughout the operation, measured with an oxygen analyser. Blood gas determinations were done frequently during the operation, and fluid loss was

\section{TABLE III}

Anaesthetic Problems in Cancer Patients

I. Cardiovascular

Pericardial effusion

Drug induced cardiomyopathy

Drug induced arrhythmias

\section{Respiratory}

Atelactasis

Pleural effusion

Drug induced pulmonary dysfunction

III. Gastrointestinal and renal

Cachexia

Fluid and electrolyte

Hepatic damage

Renal damage

IV. Haemopoietic

Anaemia

Granulocytopenia

Thrombocytopenia

Hypercoagulability

V. Metabolic and endocrine

Hypoglycaemia

Hypercalcaemia, hypocalcaemia, hyperkalaemia Hypertension

Cushing syndrome, SIADH, DI, Carcinoid syndrome

VI. Central nervous

Neuropathy

Myasthenia gravis

Myasthenia syndrome

Spinal metastases

Brain metastases

VII. Drug interaction 
replaced carefully. Postoperatively the patients were maintained on room air or on $\mathrm{FIo}_{2} 0.24$ regulated by Venti-mask. There were nodeaths in this group. ${ }^{64}$

It is suggested that antecedent bleomycin therapy in some way sensitizes the lung to levels of oxygen that are not usually detrimental.

\section{SUMMARY}

The main principle in anaesthetic management of cancer patients is caution in dosage because of the possibility of decreased cardiac and respiratory reserve, and possible obscured hepatic and renal impairment. The anaesthetic problems which should be anticipated in cancer patients who are on therapy are discussed and summarised in Table III.

An understanding of these problems ensures greater safety during operation and quicker recovery in the postoperative period.

\section{REFERENCES}

1. Cline, M.J. \& Haskell, C.M. Cancer Chemotherapy, third edition, Philadelphia, W.B. Saunders (1980).

2. Des Regato, J.A. \& Spjut, H.J. Cancer diagnosis, treatment and prognosis, fifth edition, St. Louis, C.V. Mosby (1977).

3. Goodman, L.S. \& Gillman, A. The pharmacological basis of therapeutics, fifth edition, New York, Macmillan (1975).

4. Mitls, B.A. Cyclophosphamide induced cardiomyopathy. Cancer 43 (6), 2223-6 (1979).

5. VON HoFf, D.D., ReICHERT, C.M., REDdicK, R.L., RozenCWEIG, M., Young, R.C. \& MAGGIA, F.M. Toxic effects of cis-Dichlorodiammeplatinum in Man. Cancer treatment reports 63: 1527-1531 (1979)

6. MASON, J.W. Anthracycline cardiotoxicity recognition, management and ayoidance. Comprehensive therapy 5: 64-68 (1979).

7. CarTes, S.K. Adriamycin - A review. J. of the National Cancer Inst. 55: 1265-74 (1975).

8. VoN HoFf, D.D., et al. Risk factors for Doxorubicin-induced congestive heart failure. Ann. of Int. Med. 91: 710-717 (1979).

9. ChOE, J.Y., Combs, A.B. \& Folkers, K. Potentiation of the toxicity of adriamycin by propranolol. Research communications in Chemical Pathology and Pharmacology 21: 578-580 (1978).

10. Minow, R.A., Benjamin, R.S. \& Gottlifb, J.A. Adriamycin cardiomyopathy - an overview with determination of risk factors. Cancer Chemother Rep. 6: 192-200 (1975).

11. Rinehart, J., Lewis, R. \& Balcerzak, S.P. Adriamycin cardiotoxicity in man. Ann Int. Med. 81: 475-8 (1974).

12. JoNes, S.E., Ewy, G.A. \& Groves, B.M Echocardiographic detection of adriamycin heart disease. Proc. Am. Assoc. Cancer Res. 16: 228 (1975).

13. Hankins, D.G., Macdonald, F.M. \& Drage, C.W. Pulmonary toxicity recurring after a six week cause of busulfan therapy and after subsequent therapy with uracil mustard. Chest 73:415 (1978).

14. Patel, H.R., Shah, P.C Rhee, H.L., SasSOON, H. \& RAO, K. P. Cyclophosphamide therapy and interstitial pulmonary fibrosis. Ca. 38: 1542-9 (1976)

15. Cole, S.R., Myers, T.J. \& Klatsky, A.V. Pulmonary disease with chlorambucil Therapy. Ca. 4I: 45509 (1978)

16. Nesbit, M., KRIVIT, W., Heyn, R. \& ShaRP, H. Acute and chronic effects of methotrexate on hepatic, pulmonary and skeletal system. Cancer 37: 1048-1054 (1976).

17. Dukes, M.N.G. Side effects of Drugs Annual I, 9th Edition, Amsterdam, Excerpta Media.

18. Crooke, S.T. \& Bradner, W.T. Bleomycin: A review. J. Med. 7: 333-428 (1976).

19. DewYs, W. Working conference on anorexia and cachexia of neoplastic disease. Cancer Res. 30: 2816-2818 (1970)

20. Livingston, R.B. \& CARTER, S.K. Single agents in cancer chemotherapy. New York, Plenum Publishing Corp. (1970).

21. Carter, S.K., BaKowski, M.T. \& Hellman, K. Chemotherapy of Cancer, New York. John Wiley and sons (1977).

22. McLl vanie, S.K. \& MacCarthy, J.D. Hepatitis in association with prolonged 6 mercaptopurine therapy. Blood 14:80-90 (1959).

23. Slavin, R.E., Millan, J.C. \& Mullins, G.M. Pathology of high dose intermittent cyclophosphamide therapy. Hum. Pathol. 6: 693-709 (1975).

24. Hersh, E.M., Wong, V.G., Henderson, E.S \& Freireich, E.J. Hepatotoxic effects of methotrexate. Cancer 19: 600-606 (1966).

25. KeNNEDY, B.J. Metabolic and toxic effects of mithramycin during tumour therapy. Am. J. Med. 49: 494-503 (1970)

26. Capizz, R.L., Bertino, J.R. \& HandschuMaCHER, R.E. L-Asparaginase. Ann. Rev. Med. 21: 433-44 (1970).

27. Broder, L.E. \& Carter, S.K. Pancreatic islet cell carcinoma II. Results of therapy with streptozotocin in 50\% patients. Ann. Intern Med. 79 : 108-18 (1973).

28. Condit, P.T., Chanes, R.E. \& Joel, W. Renal toxicity of Methotrexate. CA. 23: 126-31 (1969).

29. SILVER, R.T., LAUPER, R.D. \& JAROWSKI, C.I A synopsis of cancer chemotherapy, New York, Dun Donnelley (1977).

30. Schein, P.S., O'ConNell, M.J., Blom, et al. Clinical antitumour activity and toxicity of streptozotocin. Cancer 34: 993-1000 (1974).

31. Sartorelli, A.C. \& Johns, D.G. Antineoplastic and immunosuppressive agent. Part I, New York,-Springer-Verlag (1974).

32. HaRris, J.E. \& Sinkovics, J.G. The immunology of malignant disease. 2nd edition, St. Louis, C.V. Mosby (1976).

33. Peck, S.D. \& Reiquam, C.W. Disseminated 
intravascular coagulation in cancer patients: Supportive evidence. Cancer 3I: 1114-1119 (1973).

34. GOODNIGHT, S. H. JR. Bleeding and intravascular clotting in malignancy: a review. Ann. N.Y. Acad. Sci. 230: 271-288 (1974).

35. Monto, R.W., Talley, R.W., Caldwell, M.J., Levin, W.C. \& GUest, M.M. Observations on the mechanism of haemorhagic toxicity in mithramycin toxicity. Can. Res. 29:697-700 (1969).

36. Marks, L.J., Steinke, J., Podolsky, S., et al Hypoglycaemia associated with neoplastic. Ann. N.Y. Acad. Sci. 230: 147-160 (1974)

37. Silva, O.L., Becker, K.L., Primack, A., et al. Ectopic production of calcitonin by oat cell carcinoma. N.E.J.M. 290: 1122-1124 (1974)

38. Hall, T.C., Griffiths, C.T. \& Petranek, Jr. Hypocalcaemia - an unusual metabolic complication of breast cancer. N.E.J.M. 275: 14741477 (1966)

39. Singer, F.R., Bethune, J.E. \& MASSRY, S.G. Hypercalcaemia and hypocalcaemia. Clini. Nephrol. 7: 154-162 (1977).

40. Chisholm, G.D. Nephrogenic ridge tumours and their syndromes. Ann. N.Y. Acad. Sci. 230: 403-423 (1974).

41. STOLINSKY, D.C. Paraneoplastic syndromes. West. J. Med. 132: 189-208 (1980)

42. Dyck, P.J., Thomas, P.K. \& LamberT, E.H. Peripheral neuropathy: Philadelphia, W.B. Saunders (1975).

43. TYLER, H.R. Paraneoplastic syndromes of nerve, muscle and neuromuscular junction. Ann. N.Y. Acad. Sci. 230: 348-357 (1974).

44. WeISS, H.D., WALKER, M.D. \& WIERNIK, P.H. Neurotoxicity of commonly used antineoplastic agents. N.E.J.M. 291: 75-81 (1974)

45. Kedar, A., Cohen, M.E. \& Freeman, A.I. Peripheral neuropathy as a complication of cisDichlorodiammine-platinum treatment: a case report. Cancer treatment reports. 62: 819-821 (1978).

46. Siemsen, J.K. \& Meister, L. Bronchogenic carcinoma associated with severe orthostatic hypotension. Ann. Int. Med. 58: 669-676 (1963).

47. Eaton, L.M. \& Lambert, E.H. Electromyography and electric stimulation of nerves in diseases of motor unit. J.A.M.A. 163: 1117-1124 (1957).

48. Fukuhara, N., Tekamor, M., Gutmann, I., et al. Eaton-Lambert syndrome: Ultrastructural study of the motor end-plates. Arch. Neurol, 27: 67-78 (1972)

49. Lipton, A., Hepner, G.W., White, D.S \& HARVEY, H.A. Decreased hepatic drug demeth- ylation in patients receiving chemotherapy. Cancer 41: 1680-84 (1978).

50. Mosedale, B. \& Smith, M.A. Corynebacterium parvum and anaesthetics. Lancet 1 (7899): 168 (1975).

51. Wetstone, H.J., LAMotTA, R.V., et al. Studies of cholinesterase activity, V. Serum cholinesterase in patients with carcinoma. Annals Int. Med. 52: 102-125 (1960)

52. Mone, J.G. \& MATHRIE, W.E. Qualitative and quantitative defects of pseudocholinesterase activity. Anaesthesia 22: 55-68 (1967).

53. WALKER, I.R., ZAPF, P.W. \& MACKAY, I.R. Cyclophosphamide, cholinesterase and anaesthesia. Aust. N.Z. J. Med. 3: 247-251 (1972).

54. Gurman, G.M. Prolonged apnoea after succinylcholine in a case treated with cystostatics for cancer. Anaes. Analgesia. 51: $761-765$ (1972).

55. Wang, R. \& Ross, C.A. Prolonged apnoea following succinylcholine in cancer patients receiving AB 132. Anaesthesiology 24: 363-367 (1963).

56. ZAIGMOND, E.K. \& RoBins, G. The effects of a series of anticancer drugs on plasma cholinesterase activity. Can. Anaesth. Soc. J. 19: 75-82 (1972).

57. VETTEN, K.B. Immunosuppressive therapy and anaesthesia. S.A. Med. J. 47: 767-770 (1973).

58. Bennett, E.J., Schmidt, G.B., PAtel, K.P. \& GRUNDY, E.M. Muscle relaxants, myasthenia, and mustards. Anesthesiology 46: 220-221 (1977).

59. Clement, J.G \& Colmoun, E.H. Presynaptic effects of the aziridinium ion of acetycholine mustard on the phrenic nerve rat diaphragm preparation. Can. J. Physiol. Pharmacol. 53: 264-272 (1975).

60. Colmoun, E.H. \& RYLett, B.J. Further facts about neuromuscular blockade by nitrogen mustard and by thiotepa. Anaesthesiology 48: 381 (1978).

61. Housten, P.D. Drug interactions. Fourth edition, Philadelphia, Lea and Febriger (1979).

62. Mann, A.M. \& Hutchison, J.L. Manic reaction associated with procarbazine hydrochloride therapy of Hodgkin's disease. Can. Med. Assoc. J. 97: 1350 (1967).

63. Goldiner, P.L., Carlon, G.C., Critkovic, E., SCHWEIZER, O. \& HOWLAND, W.S. Factor influencing postoperative morbidity and mortality in patient treated with bleomycin. Brit. Med. J. I: (6128): 1664-7 (1978).

64. Goldiner, P.L. \& SCHweizer, O. The hazards of anaesthetics and surgery in bleomycin-treated patients. Seminars in Oncology 6: 121-124 (1979). 